\title{
Commentary
}

\section{The American Heart Association advisory on $n-6$ fatty acids: evidence based or biased evidence?}

The essentiality of the $n-6$ fatty acid, linoleic acid, was established about 80 years ago ${ }^{(1,2)}$; the essentiality of the $n-3$ analogue, $\alpha$-linolenic acid, became accepted rather later ${ }^{(3,4)}$. The intakes of these fatty acids necessary to avoid deficiency are quite low (estimated to be 1 and $0.2 \%$ of energy intake, respectively, corresponding to intakes in adults of about 2 and $0.4 \mathrm{~g} / \mathrm{d}$ ), and all diets should obviously provide at least these amounts. Classic studies by Keys, Hegsted, Katan and others have established that several SFA raise blood cholesterol and LDL concentrations, while linoleic acid lowers these concentrations ${ }^{(5)}$. The differential effects of saturated and linoleic acids on the blood cholesterol concentration are expected to affect the risk of CVD and have been reflected in dietary recommendations. In the UK, the relevant recommendations are 'saturated fatty acids should provide less than $10 \%$ of total dietary energy', 'cis-PUFAs should continue to provide an average of $6 \%$ of total dietary energy and be derived from a mixture of $n-6$ and $n-3$ PUFAs' and 'dietary intake of PUFAs by individuals should not exceed $10 \%$ of total energy ${ }^{(6)}$. The realisation of the effect of linoleic acid on blood cholesterol concentration and the anticipation that an increased intake of linoleic acid at the expense of SFA would benefit cardiovascular health paved the way for the introduction of margarines and linoleic acid-rich vegetable oils into the human food chain with associated heavy marketing. The result was a large increase in the intake of linoleic acid in the population over the period from the 1960s to 1990. In the USA, the average daily intake of linoleic acid among adults increased from about 5 to about $8 \%$ of energy between 1960 and 1990, and the current average intake in adults is about $15 \mathrm{~g} / \mathrm{d}^{(7)}$. The average intake of linoleic acid among adults in the UK is currently about $5.4 \%$ of energy or $13 \mathrm{~g} / \mathrm{d}$ in men and $9.5 \mathrm{~g} / \mathrm{d}$ in women ${ }^{(8)}$.

Despite the enthusiasm for increasing linoleic acid intake, some doubts remained when the recommendations for linoleic acid intake were established. First an increased linoleic acid content of LDL increases its sensitivity to oxidation ${ }^{(9)}$, and it is the oxidised LDL that is involved in atherosclerotic plaque growth. Hence, an increase in linoleic acid intake could actually promote plaque growth and CVD. Second, there was some evidence that linoleic acid could promote certain cancers, especially in animal models ${ }^{(10)}$. These doubts were captured in an additional, often ignored, recommendation related to PUFA intake in the UK: 'there is reason to be cautious about high intakes of $n-6$ PUFAs, and we recommend that the proportion of the population consuming in excess of about $10 \%$ of energy [as $n$-6 PUFAs] should not increase ${ }^{(11)}$.
Two other scientific developments have had an impact on the general view that $n-6$ fatty acids, in general, and linoleic acid, in particular, are, almost by definition, associated with health. The first scientific development was the discovery of the actions of eicosanoid mediators derived from arachidonic acid. Arachidonic acid is produced by the metabolism of linoleic acid, and the arachidonic acid-derived eicosanoids are involved in many physiological and pathophysiological responses including inflammation and thrombosis; arachidonic acid metabolism is the target of several pharmaceutical agents. Since both inflammation and thrombosis are involved in atherosclerotic plaque growth and rupture, once again, this suggests the possibility of an increase in cardiovascular risk with increased $n-6$ fatty acid exposure. The second scientific development was the discovery of the protective effects of marine $n-3$ fatty acids towards CVD and the improved understanding of their mechanisms of action $^{(12,13)}$. An increased intake of marine $n-3$ fatty acids lowers arachidonic acid status and interferes with arachidonic acid metabolism, decreasing the production of pro-inflammatory and pro-thrombotic mediators ${ }^{(14)}$. Hence, the recognised health benefits of marine $n-3$ fatty acids and the realisation that they often work by 'antagonising' $n-6$ fatty acids generated a perception of ' $n-3$ good, $n-6$ bad' ${ }^{\text {'(15,16) }}$.

This status quo was perturbed last year when the American Heart Association (AHA) published an advisory on $n-6$ fatty acids and cardiovascular risk $^{(17)}$. The advisory dismissed concerns about inflammation, thrombosis and LDL oxidation. Each of these aspects requires a deeper debate given the increased evidence base that currently exists. However, the main component of the advisory was devoted to the evaluation of observational studies and randomised controlled trials (RCT) of $n-6$ fatty acids and CHD events. It is generally accepted that RCT provide the highest level of evidence of cause and effect. The AHA advisory evaluated the findings of nine RCT published from 1965 to 1989 and noted that at least five of these trials had design limitations; the latter limitations included the simultaneous use of plant or marine $n$-3 fatty acids in some studies. Although these limitations appear not to have been considered in developing the advisory, they may have influenced its major scientific conclusion ('replacing saturated fatty acids with PUFAs lowered CHD events'), which is clearly not an n-6 fatty acid (or linoleic acid)-specific summary statement, and so somewhat blurs the boundaries between PUFA, n-6 PUFA and linoleic acid. The advisory states that "consumption of at least $5 \%$ to $10 \%$ of energy from $n-6$ PUFAs reduces risk of CHD relative to lower intakes' and that 'to reduce $n-6$ 
PUFA intakes from their current levels would be more likely to increase than to decrease risk for CHD'.

An article in this issue of the $B J N$ addresses the question of linoleic acid and CHD mortality risk, in the light of the AHA advisory $^{(18)}$. The initiation of the work of Ramsden et al. is their recognition that the $n-6$ PUFA advisory was largely based on the evidence from RCT that often did not address the question of $n-6$ PUFA or linoleic acid in isolation, but rather included mixtures of $n-6$ and $n-3$ PUFA. Ramsden et al. have evaluated the findings of studies specifically addressing the impact of increased linoleic acid intake separately from those that included linoleic acid in combination with $n-3$ fatty acids. Their efforts involved extensive detective work that included identification and use of food composition data from the locations and periods when several of the studies were performed, often over 40 years ago, and contacting original researchers of some of the older studies in order to clarify uncertain points. This scholarly approach, combined with the appreciations that (i) the terms PUFA and n-6 PUFA mean different things and (ii) linoleic acid alone and linoleic acid in combination with $n-3$ fatty acids may produce different findings, has yielded a different conclusion from the AHA advisory: 'advice to specifically increase $n-6$ PUFA intake, based on mixed data, is unlikely to provide the intended benefits, and may actually increase the risks of CHD and death'. This piece of work by Ramsden et al. is to be applauded and will, it is hoped, open a healthy scientific debate on this important matter.

$$
\begin{array}{r}
\text { Philip C. Calder } \\
\text { Institute of Human Nutrition } \\
\text { School of Medicine } \\
\text { University of Southampton } \\
\text { IDS Building } \\
\text { MP887 Southampton General Hospital } \\
\text { Tremona Road } \\
\text { Southampton SO16 6YD } \\
\text { UK } \\
\text { email pcc@ soton.ac.uk }
\end{array}
$$

\section{Conflict of interest}

The author serves on the Danone Scientific Advisory Board on Baby Nutrition, acts as a consultant to the Danone Research Centre for Specialised Nutrition, and in the past 5 years has acted as a consultant to Mead Johnson Nutritionals, Vifor Pharma, Equazen and Amarin Corporation. He has received speaking honoraria from Solvay Healthcare, Solvay Pharmaceuticals, Pronova Biocare, Fresenius Kabi, B. Braun, Abbott Nutrition, Baxter Healthcare, Nestlé and Unilever. He currently receives research funding in the area of fatty acids from the Food Standards Agency, the European Commission, Vifor Pharma and Abbott Nutrition. He is elected President of the International Society for the Study of Fatty Acids and Lipids, an organisation that is partly supported by corporate membership fees, mainly the food and supplement industries. He is currently, or has recently been, a member of four expert groups of ILSI Europe, chairing two of these; ILSI Europe is funded in part by the European food industry.

\section{References}

1. Burr GO \& Burr MM (1929) A new deficiency disease produced by the rigid exclusion of fat from the diet. $J$ Biol Chem $\mathbf{8 2}$, $345-367$.

2. Burr GO \& Burr MM (1930) The nature and role of the fatty acids essential in nutrition. $J$ Biol Chem 86, 587-621.

3. Pudelkewicz C, Seufert J \& Holman RT (1968) Requirements of the female rat for linoleic and linolenic acids. J Nutr 94, $138-146$.

4. Holman RT, Johnson SB \& Hatch TF (1982) A case of human linolenic acid deficiency involving neurological abnormalities. Am J Clin Nutr 35, 617-623.

5. Katan MB, Zock PL \& Mensink RP (1995) Dietary oils, serum lipoproteins, and coronary heart disease. Am J Clin Nutr 61, 1368S-1373S.

6. Report of the Panel on DRVs of the Committee on Medical Aspects of Food Policy (COMA) of the Department of Health (1991) Dietary Reference Values (DRVs) for Food Energy and Nutrients for the UK. Report on Health and Social Subjects no. 41. London: The Stationery Office.

7. Mosfegh A, Goldman J \& Cleveland L (2005) What We Eat in America, NHANES 2001-2002. Usual Nutrient Intake from Foods as Compared to Dietary Reference Intakes. Washington, DC: US Department of Agriculture, Agricultural Research Service.

8. Henderson L, Gregory J, Irving K, et al. (2003) The National Diet and Nutrition Survey: Adults Aged 19 to 64 Years Energy, Protein, Carbohydrate, Fat and Alcohol Intake. London: The Stationery Office.

9. Tsimikas S, Philis-Tsimikas A, Alexopoulos S, et al. (1999) LDL isolated from Greek subjects on a typical diet or from American subjects on an oleate-supplemented diet induces less monocyte chemotaxis and adhesion when exposed to oxidative stress. Arterioscler Thromb Vasc Biol 19, 122-130.

10. Welsch CW (1992) Relationship between dietary fat and experimental mammary tumorigenesis: a review and critique. Cancer Res 52, 2040s-2048s.

11. Report of the Cardiovascular Review Group of the Committee on Medical Aspects of Food Policy (COMA) of the Department of Health (1994) Nutritional Aspects of Cardiovascular Disease. Report on Health and Social Subjects no. 46. London: The Stationery Office.

12. Calder PC (2004) n-3 Fatty acids and cardiovascular disease: evidence explained and mechanisms explored. Clin Sci 107, $1-11$.

13. Saravanan P, Davidson NC, Schmidt EB, et al. (2010) Cardiovascular effects of marine omega-3 fatty acids. Lancet 376, 540-550.

14. Calder PC \& Yaqoob P (2009) Understanding omega-3 polyunsaturated fatty acids. Postgrad Med 121, 148-157.

15. Simopoulos AP (2002) The importance of the ratio of omega6/omega-3 essential fatty acids. Biomed Pharmacother 56, $365-379$.

16. Lands WE (2003) Primary prevention in cardiovascular disease: moving out of the shadows of the truth about death. Nutr Metab Cardiovasc Dis 13, 154-164.

17. Harris WS, Mozaffarian D, Rimm E, et al. (2009) n-6 fatty acids and risk for cardiovascular disease: a science advisory from the American Heart Association Nutrition Subcommittee of the Council on Nutrition. Physical Activity, and Metabolism; Council on Cardiovascular Nursing; and Council on Epidemiology and Prevention. Circulation 119, 902-907.

18. Ramsden CE, Hibbeln JR, Majchrzak SF, et al. (2010) n-6 Fatty acid-specific and mixed polyunsaturate dietary interventions have different effects on CHD risk: a meta-analysis of randomised controlled trials. Br J Nutr 104, 1586-1600. 